Article

\title{
Closing Data Gaps with Citizen Science? Findings from the Danube Region ${ }^{+}$
}

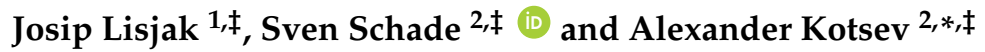 \\ 1 City of Požega, Department for Communal System and Management, Požega HR-34000, Croatia; \\ josip.lisjak@pozega.hr \\ 2 European Commission, Joint Research Centre, Digital Economy Unit, Ispra 21027, Italy; \\ s.schade@ec.europa.eu \\ * Correspondence: alexander.kotsev@ec.europa.eu; Tel.: +39-0332-78-9069 \\ + The views expressed are purely those of the authors and may not in any circumstances be regarded as \\ stating an official position of the European Commission. \\ $\ddagger$ All authors contributed equally to this work.
}

Received: 23 May 2017; Accepted: 11 August 2017; Published: 1 September 2017

\begin{abstract}
Although data is increasingly shared online and accessible for re-use, we still witness heterogeneous coverage of thematic areas and geographic regions. This especially becomes an issue when data is needed for large territories and including different nations, as, for example, required to support macro-regional development policies. Once identified, data gaps might be closed using different approaches. Existing — but so far non accessible—data might be made available; new public sector information could be gathered; or data might be acquired from the private sector. Our work explores a fourth option: closing data gaps with direct contributions from citizen (Citizen Science). This work summarizes a particular case study that was conducted in 2016 in the Danube Region. We provide a gap analysis over an existing macro-regional data infrastructure, and examine potential Citizen Science approaches that might help to close these gaps. We highlight already existing Citizen Science projects that could address a large part of the identified gaps, and suggest one particular new application in order to indicate how a-so far uncovered-gap might be approached. This new application addresses bioenergy as a particular field of the circular economy. On this basis we discuss the emerging opportunities and challenges for this particular way of public participation in regional development policy. We close by highlighting areas for future research.
\end{abstract}

Keywords: Citizen Science; data gaps; spatial data infrastructures; Danube region; European Union Strategy for the Danube Region

\section{Introduction}

During the past few years, Open Data policies reached a new level. Governments across the entire globe continue to release public sector information for re-use by the public and private sector, hoping for increasing uptake and the resulting growth and innovation [1]. Whereas the current achievements are remarkable in many countries, we still witness data gaps in many different thematic areas, ranging across all economic, social and environmental domains [2]. Such gaps become even more visible when addressing macro-regional questions, because different notations follow diverse policies and are at a different stage of implementation. Furthermore, for some we might never be in the position to provide the missing data sets. Assuming that better evidence leads to better policy making, and especially that more complete data is an asset for policy, new approaches are needed in order to close the existing gaps and to support macro-regional developments.

So far, approaches to close data gaps include efforts to (i) provide access to already existing data sets; (ii) collect new public sector information with classical tools, such as land surveys; and (iii) acquire 
suitable data from the private sector. All these developments could already be observed through the emerging spatial data infrastructures (SDI) [3] on multiple geographic scales (e.g., municipal, regional, national, and international), which deserves more attention.. However, there is a fourth option available. Citizen Science is increasingly seen as a complement, and even substitute, to data from such traditional sources [4]. The penetration of smart devices, combined with the widespread use of socially-enabled Internet platforms and the rapidly developing technological scenery are together leading to unprecedented advancements in the ways we collect, transfer and make sense of data [5]. Individuals are no longer passive users of data generated by a designated institution on their behalf. On the contrary, they play a far more direct role in the creation and utilisation of content.

From this perspective, citizens are increasingly in need of data, as they want to play a more significant role in forming policies, but also in their implementation and control. Data is therefore to be seen within the context of the direct democracy paradigm [6]. It is nowadays more accessible than ever which implicitly leads to a better insight on general and individual decisions and their consequences [7]. Today, citizens do approach governmental bodies and public administration more intensively with their demands, complaints and requests for protection of their rights. Those demands cover various fields such as communal issues, social rights, health, environment protection. There are multiple challenges associated with the citizen participation within the governance process (see e.g., [8,9]). Citizens use available data and are an increasingly active partner in public sector management. It is therefore meaningful that they participate in data collection as well. Realising the many potential benefits from engaging with citizens, we conducted a study in the Danube region with two interdependent objectives. On one hand, we analyse the possible data gaps within the study area, for example, related to areas such as environmental protection, energy production and air quality. On the other hand, we elaborate on how some of the most prominent gaps might benefit from some sort of community engagement, such as the voluntary measurement of the exhaust of cars, air quality parameters, or the mapping of the current production of renewable energy in neighbourhoods. In meeting our objectives we studied the pan-Danubian open data portal put in place within the Danube Reference Data and Services Infrastructure project-DRDSI [10]. Our intention was not to completely fill existing gaps with Citizen Science data, as this is unrealistic given the vastness of the areas addressed (including air, water, energy and many more). Instead, we (i) emphasised on the importance of citizen engagement as an alternative channel for acquisition of data, and (ii) provided a theoretical construct on how the identified data gaps may be addressed, and (iii) offer several concrete examples on how activities involving the active participation of citizens would improve the current situation.

The following sections first present the background underlying the core of our investigations (Section 2). After introducing dedicated activities in the Danube Region, we present the results of our initial gap analysis of data availability in the region (Section 3). This is the basis for a first matchmaking of these gaps with already existing Citizen Science activities, and a proposal to address one of the gaps, which is related to bioeconomy, in Section 4 . Section 5 discusses our findings, especially considering the (i) emerging opportunities and (ii) challenges for this particular way of public participation in relational development policy. The article closes with our main conclusions and an outline of future work (Section 6) We particularly underlining that this is a promising baseline for more detailed investigations and actions for addressing data gaps using Citizen Science.

\section{Background}

Our study focuses on the Danube macro-region. We benefit from our past support to macro-regional data sharing, but can also tap into a wide range of ongoing Citizen Science activities only partly coming from within the region.

\subsection{Study Area}

Geographically our analyses cover the area of the European Union Strategy for the Danube region-EUSDR [11]. It spans over 14 countries-Austria, Bosnia and Herzegovina, Bulgaria, Croatia, 
Czech Republic, Germany (Baden-Württemberg and Bavaria lander.), Hungary, Moldova, Montenegro, Romania, Slovenia, Slovakia, Serbia and Ukraine (Oblasts of Chernivtsi, Ivano-Frankivsk, Odessa and Zakarpattia.) (Figure 1). As an initiative, endorsed by the EU Member States at the General Affairs Council on 13 April 2011, the EUSDR functions through the commitment of all 14 neighbouring countries for joint actions towards regional development, taking into consideration each region's competitive advantages. A governance body is also established to coordinate those activities on a macro scale [11]. The strategy is thematically subdivided into 11 priority areas (PA) that cover a broad range of topics with some relevance to macro-regional development, such as environmental protection, transportation, capacity building, and competitiveness.

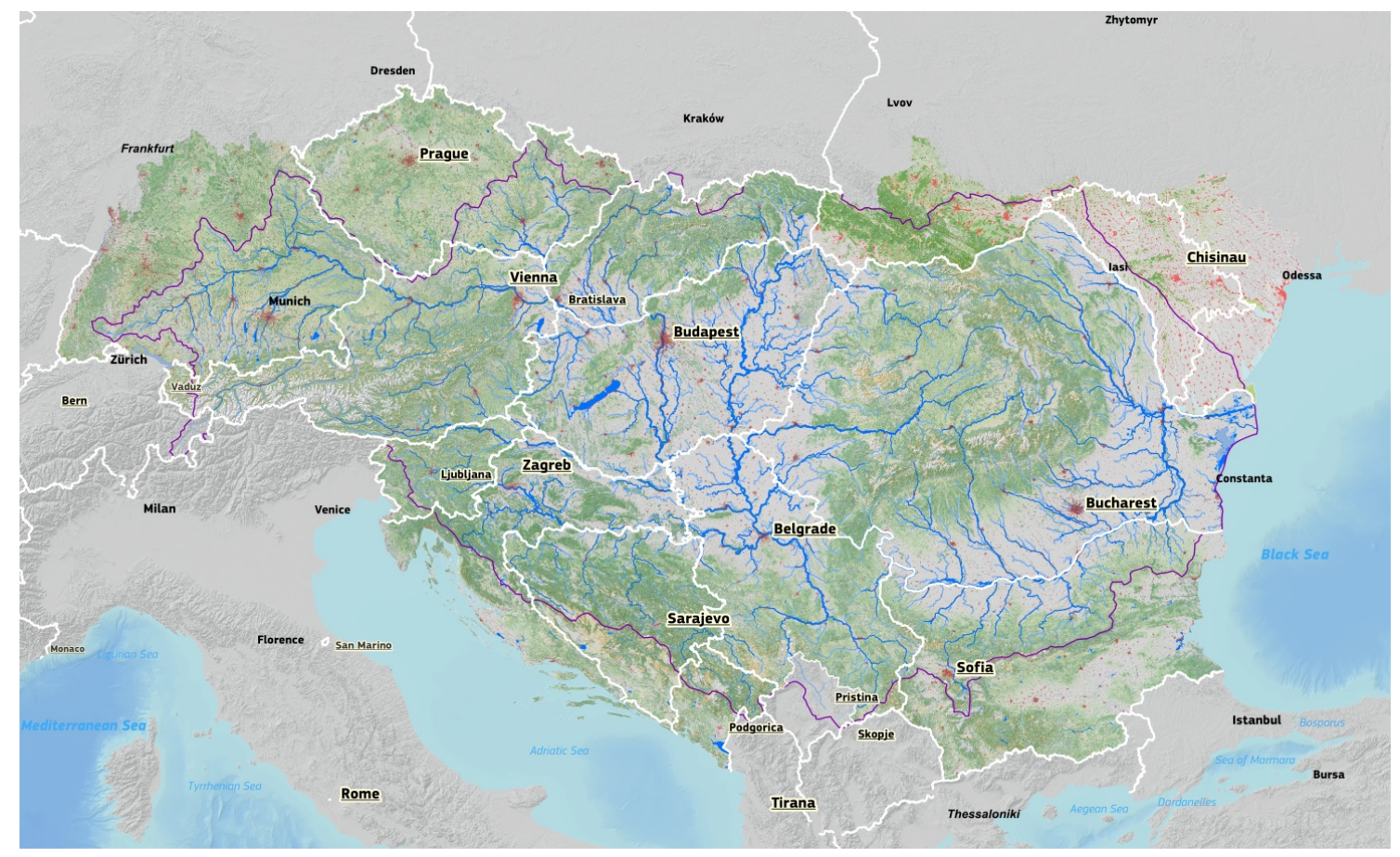

Figure 1. Territorial dimension of the EU Strategy for the Danube Region. Source: [12].

Within this broad context, the access to timely, accurate and comparable data for all 14 countries is a cross-cutting issue that is of critical importance for the overall implementation of the strategy. Benchmarking, monitoring progress towards predefined goals and identifying the advantages of each country, region or city in the study area are just a few examples of the possible use of data on the macro-regional level. At the same time, data infrastructures in the study area are heterogeneous, shaped by different cultures, traditions, languages and organisational settings.

\subsection{Danube Reference Data and Services Infrastructure (DRDSI)}

\subsubsection{Policy Context}

Data is of critical importance for the successful implementation of regional policy. In the absence of high quality (geospatial) data, it would hardly be possible for policy makers to identify the competitive advantages or disadvantages of a given region. Furthermore, as already mentioned, comparable territorially referenced data is needed in order to define baselines, and monitor progress in meeting the policy objectives against the baselines. At the same time, the identification, acquisition and use of data for the study area turned out to be a highly challenging task which required series of interdependent tasks (organisational, technological and legal) to be addressed in a coordinated manner. Considering the above, a project was put in place by the Joint Research Centre (JRC) of the European Commission. The project-Danube Reference Data and Services Infrastructure-was implemented in 
the period 2014-2016 with the overall objective to engage with stakeholders in the Danube region and work towards the establishment of a macro-regional data infrastructure addressing, at least in part, the challenges highlighted above.

The central access point of the data infrastructure was an open data portal that eases the access to various resources through a single entry point (Figure 2). A network of experts-Danube_Net-was also established with representatives in each country. They acted as 'ambassadors' of open data and worked with stakeholders on a national level.
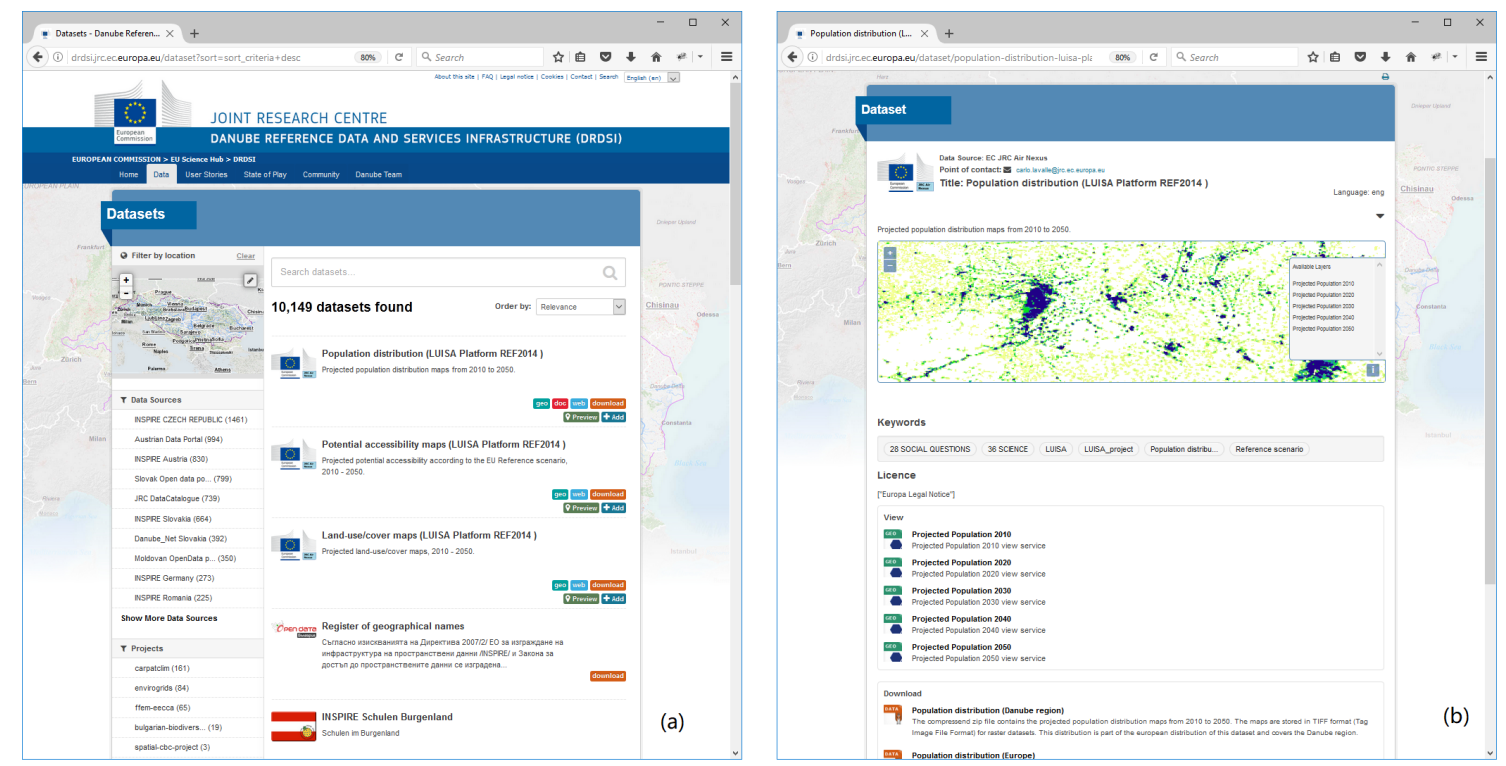

Figure 2. User interface of DRDSI. List of available datasets (a) and details about one particular entry (b). Source: [10].

\subsubsection{DRDSI Implementation}

The open data platform was metadata-driven. Metadata was (i) harvested from external sources, (ii) processed and stored internally, (iii) served through standardised web services, and (iv) exposed through a front-end. The software tools which were used included the open source CKAN (fronted), GeoNetwork open source (backend), and PostgreSQL (metadata storage). A semi-automated process was put in place for harvesting the Catalogue Services for the Web (CSW) provided by GeoNetwork, taking advantage of the CKAN geospatial plugin.

An Extract-Transform-Load (ETL) process was put in place in order to acquire, process, store and expose metadata records from heterogeneous sources (Figure 3.). The sources included standardised services (following the specifications of the Open Geospatial Consortium), proprietary solutions (ESRI RESTful services), as well as metadata collected by the Danube_Net network of experts. The acquired metadata was stored in a PostgreSQL relational database. An overview of the content is provided under Section 3.1.1 below. 


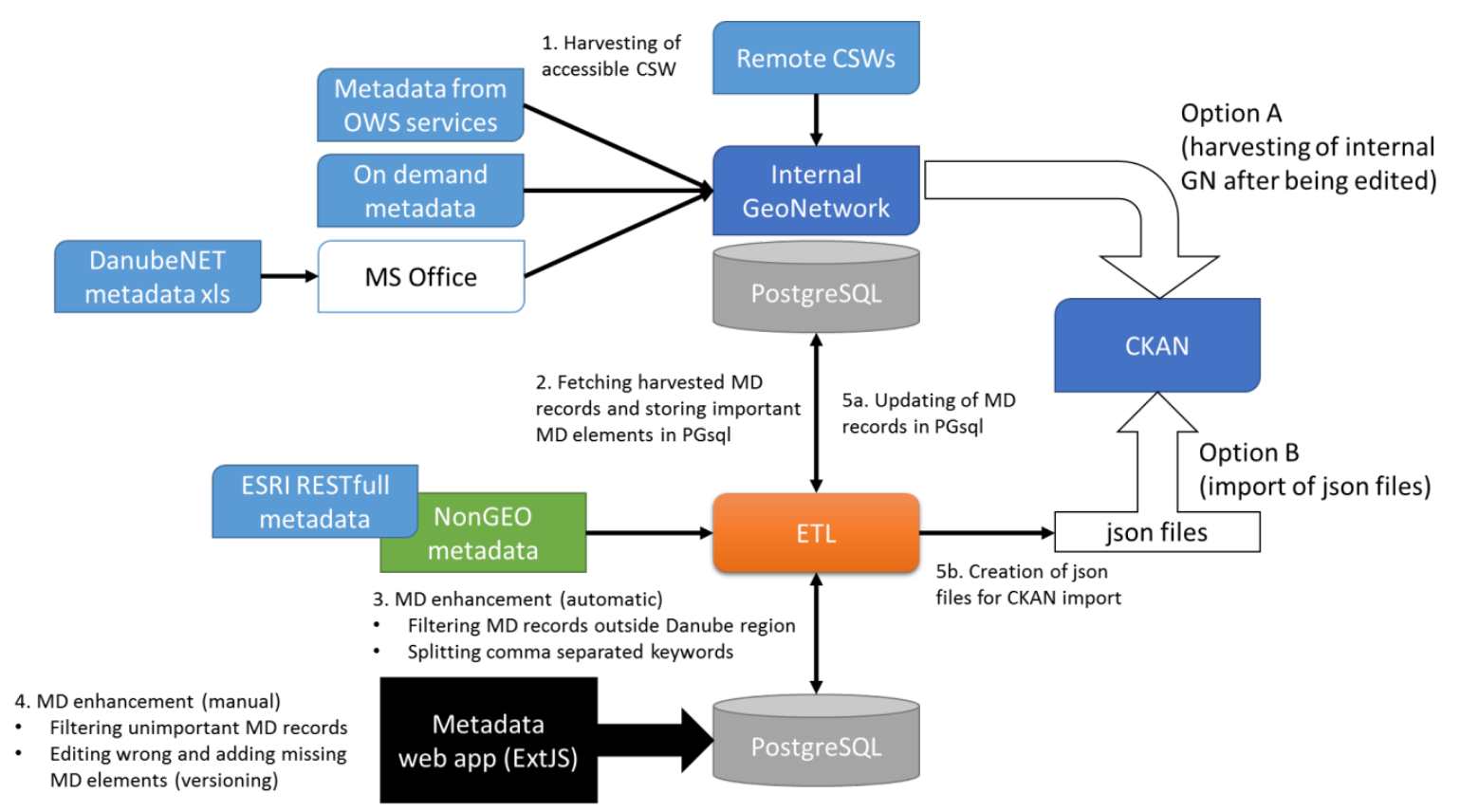

Figure 3. Architecture of the Danube Reference Data and Services infrastructure. Source: [13].

\subsection{Citizen Science}

\subsubsection{What Is Citizen Science?}

Citizen Science is a broad term, which considers that citizens can participate in the scientific research process in different ways: as observers, as funders, in identifying images or analysing data, or through providing data themselves [14]. This allows for the democratisation of science, and is also linked to stakeholders' engagement and public participation. The European Commission places it as part of Open Science [15], which is under the scope of the Digital Single Market through the 'Digital Economy and Society' priority of European Commission [16].

The notion of Citizen Science is often related to terms "crowd-sourcing" and "volunteer geographic information". For the purpose of clear understanding, crowd-sourcing is a method of mass data collection, while volunteer geographic information-VGI is limited to geographic/spatial Citizen Science only. These are clear distinctions, but the terms are nonetheless closely related. An analysis of the related terminology and its use in scientific publications has recently been published [17].

The history and rise of Citizen Science has already been well explained by authors such as Silvertown [18], and Bonney et al. [19]. In summary, the engagement of citizens in scientific activities has already a long tradition and only the term Citizen Science came to use relatively recently. Ongoing digital transformations, especially the evolution of mobile Internet and smart devices helped boosting the amount of Citizen Science activities in recent years [5].

In our work, we most often refer to the work of Craglia and Shanley [20] that integrates several of the previous categorisations, such as the one of Haklay [14] into a combined scheme. Most notably, Citizen Science is positioned into a space of Citizens' active contributions, collaborations or co-creations, which may have different motivations (see also Figure 4). 


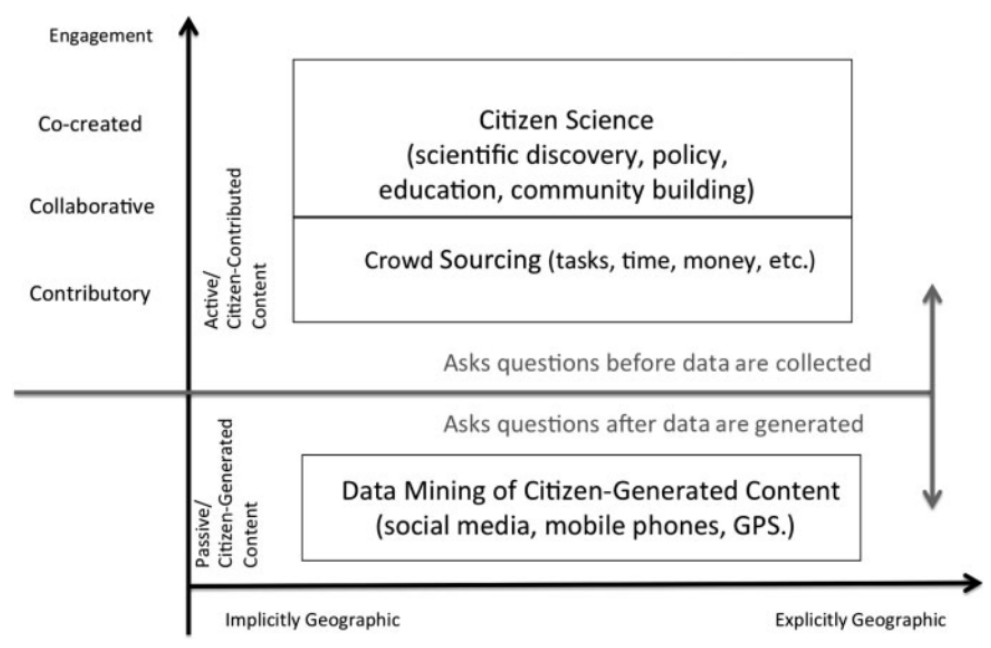

Figure 4. Schema positioning Citizen Science in the wider context of crowd-sourcing and data mining. Source: [20].

From our perspective Citizen Science is a manifestation of the collaboration of the public with researchers for common good. It is driven mainly by new technologies, and results in new knowledge and added value through the acquisition of new information. While the benefits and outcomes of specific Citizen Science activities can be manyfold, our work addresses only the narrow purpose of data gathering. Here especially following Citizen Science approaches to close data gaps, i.e., collecting data for a particular domain and inside a previously known geographic territory. We identify areas and approaches on how existing data gaps could be closed without any intention to replicate or replace existing sources.

\subsubsection{Emerging Organisational Structures for Citizen Science}

An increasing number of organisation relate themselves to Citizen Science. The League of European Research Universities (LERU) provides only one example [21]. Furthermore, a number of informal platforms are dedicated to Citizen Science activities (including, for example SciStarter [22], Atlas of Living Australia, Zooniverse, CitSci.org, or Österreich forscht). During the past few years, the continuously increasing Citizen Science activities were complemented with organisational structures. This included both thematic structures (e.g., the formation of a Citizen Science interest group within the network of European Environmental Protection Agencies, or the Citizen Science Domain Working Group of the Open Geospatial Consortium (OGC)) and geographic structures (such as national level networks in the UK, USA, Australia, Germany, Austria, Switzerland, Spain, etc., as well as a European and international network). The majority of Citizen Science activities in the Danube region occur in EU Member States. In Europe, thanks to funding from the EU, two research networks should be highlighted. One focusses on the concept of Citizens' Observatories, as a notion to include Citizens in data gathering (sensing) activities. Whereas five Citizens' Observatory projects already came to a close, four new ones started recently in order to deploy and scale up such observatories. Furthermore, project proposals to coordinate the already ongoing Citizens' Observatory initiatives are currently under evaluation. The other research network takes a slightly different approach. The Collective Awareness Platforms for Sustainability and Social Innovation (CAPS) seeks for new models to create and raise the awareness of emerging sustainability challenges. They are set up to address existing challenges through collective action. Several series of CAPs have already been funded (https://capssi.eu).

Last but not least, Citizen Science also receives much attention under the umbrella of Open Science [23]. Current research projects are funded under the notions of Responsible Research and Innovation (RII) [24] and Science with and for Society (SwfS) [25]. 


\subsubsection{Citizen Science Networks in the Danube Region}

The richest network that is relevant for the Danube Region is the European Citizen Science Association-ECSA (http:/ / ecsa.citizen-science.net). Established in 2015, ECSA gathers wide range of member and supporters in Europe and worldwide. It has a well-defined structured organisation schema, with clearly assigned roles.

ECSA conducts capacity building and training workshops and develops tools and resources for the Citizen Science community in accordance with research and coordination projects they are involved in, including the two Horizon 2020 projects Doing it Together Science (DITOs) and Landsense. ECSA also actively works on forming partnerships with other Citizen Science associations, not only in Europe, but worldwide. This especially includes the US-based CSA and the Australian ASCA.

Österreich forscht is online since 2014, and acts as a project platform. It is run by a working group of the University of Natural Resources and Life Sciences in Vienna. The platform provides information on Citizen Science and bundles over 20 Austrian Citizen Science projects. Within this framework institutions are intensively working together to network Citizen Science actors in Austria and internationally, to further promote the quality of Citizen Science, and to further develop the method. The main partner organisation that supports Österreich forscht, and vice versa, acts with similar goals is the Zentrum für Citizen Science. Besides this cooperation, Österreich forscht organises an Austrian Citizen Science Conference which is supported by the Federal Ministry of Science, Research and Economy (BMWFW) - the founder of the Zentrum für Citizen Science. These two institutions also coordinate events that encourage Citizen Science activities.

The Citizen Science platform Bürgerschaffenwissen provides information about activities to support Citizen Science in Germany. The associated component programme "GEWISS" is responsible for skills development and the establishment of a "Citizen Science strategy 2020" for Germany. GEWISS is funded by the German Ministry for Education and Research (BMBF). Additional support for the online platform is provided by the Stifterverband Deutscher Wissenschaft.

GEWISS consists of two projects conducted to support each other: A capacity-building program is focused on the evolution of Citizen Science through events and development of a strategy and practical toolkit. An online platform seeks to connect current Citizen Science projects to each other and increase public awareness of Citizen Science. Bürgerschaffenwissen issued a Green paper-Citizen Science Strategy 2020 for Germany [26] which presents the understanding, the requirements and the potential of Citizen Science in Germany. It can, in addition, be considered as an overview of the current state-of-play of Citizen Science.

The Centre for Citizen Science was established at the Austrian Agency for International Cooperation in Education and Research (OeAD-GmbH) in 2015 by the Federal Ministry of Science, Research and Economy. It serves as an information and service centre for researchers, citizens and experts from different disciplines. Another task of the centre is the cross-linking of interested communities beyond Austria [27]. The organisation provides a large information library with links to projects, literature, calls for financing, etc. There is also list of helpful tools to support the creation of Citizen Science projects, smartphone apps, and do-it-yourself tools.

\section{Analysis of Existing Data Gaps}

Within the context outlined above, data infrastructures in the study area were analysed through a stepwise approach (Figure 5) in order to identify possible gaps that might be-at least partially—covered through the engagement of citizens. The steps included (i) identification of existing data from multiple channels; (ii) classification of identified data with respect to the priorities of the EU Strategy for the Danube region; (iii) identification and analysis of possible Citizen Science contributions; and (iv) uptake of the results in support of the EUSDR. 


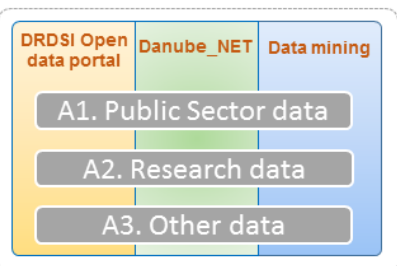

Step 1. Data discovery

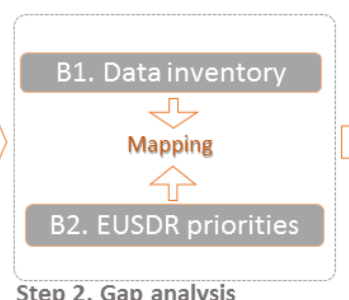

Step 2. Gap analysis
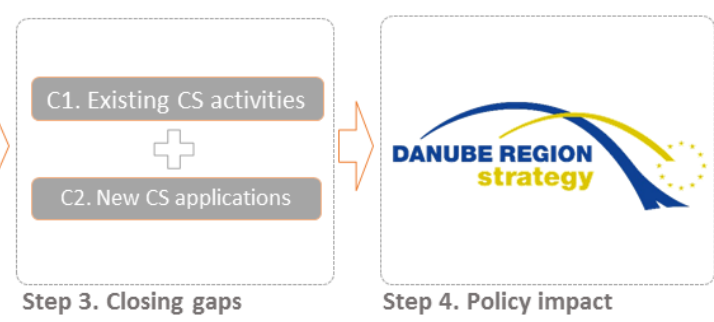

Figure 5. Approach for the identification of possibly contribution of citizens.

\subsection{Data Discovery}

We investigated multiple channels (described below) in order to identify what exists in terms of thematic data relevant to the EUSDR. The sources we used are shown through Step 1 (Figure 5). The content that was discovered consisted of (i) public sector data, (ii) results from ongoing or past research projects, as well as (iii) others, such as pan-European data-related initiatives.

It is noteworthy to highlight that having a complete picture of existing data, considering the complexity and dynamism of the macro-region, combined with the broad thematic scope of the EUSDR is a task that goes far beyond our capacity. Nonetheless, we consider that the analysis of existing data gives us a fairly good indication of the possible role that Citizen Science can play. Any follow-up investigations would need a more detailed analysis of the data that is required in each of the priority areas, and a subsequent examination of the coverage by already available data sets. We suggest that such investigations are carried out separately for each priority area.

\subsubsection{Open Data Portal}

For a period of three years the DRDSI project documented and made discoverable over 10,000 datasets through a dedicated open data portal [10]. The portal is metadata driven and the content is collected through harvesting of distributed sources such as national open data portals, national geoportals and project repositories. The majority, if not all sources (public sector resources, national geoportals, open data portals and relevant project outputs), originate from the public sector.

The distribution of data between countries is uneven, with a noteworthy higher number of datasets in the western part of the study area (Figure 6). Thematically, the datasets correspond to one or more of the priorities defined under the EUSDR [11]. That is why they are relevant to a broad range of environmental, social and economic topics. More information on the open data portal and its content is provided by Dusart et al. [12].

From our perspective, the harvested content is comprehensive and provides a representative overview on the actual data availability within the study area. Furthermore, the same approach for collecting input metadata has been applied throughout the whole macro-region, and therefore provides a comparable overview of data availability. 


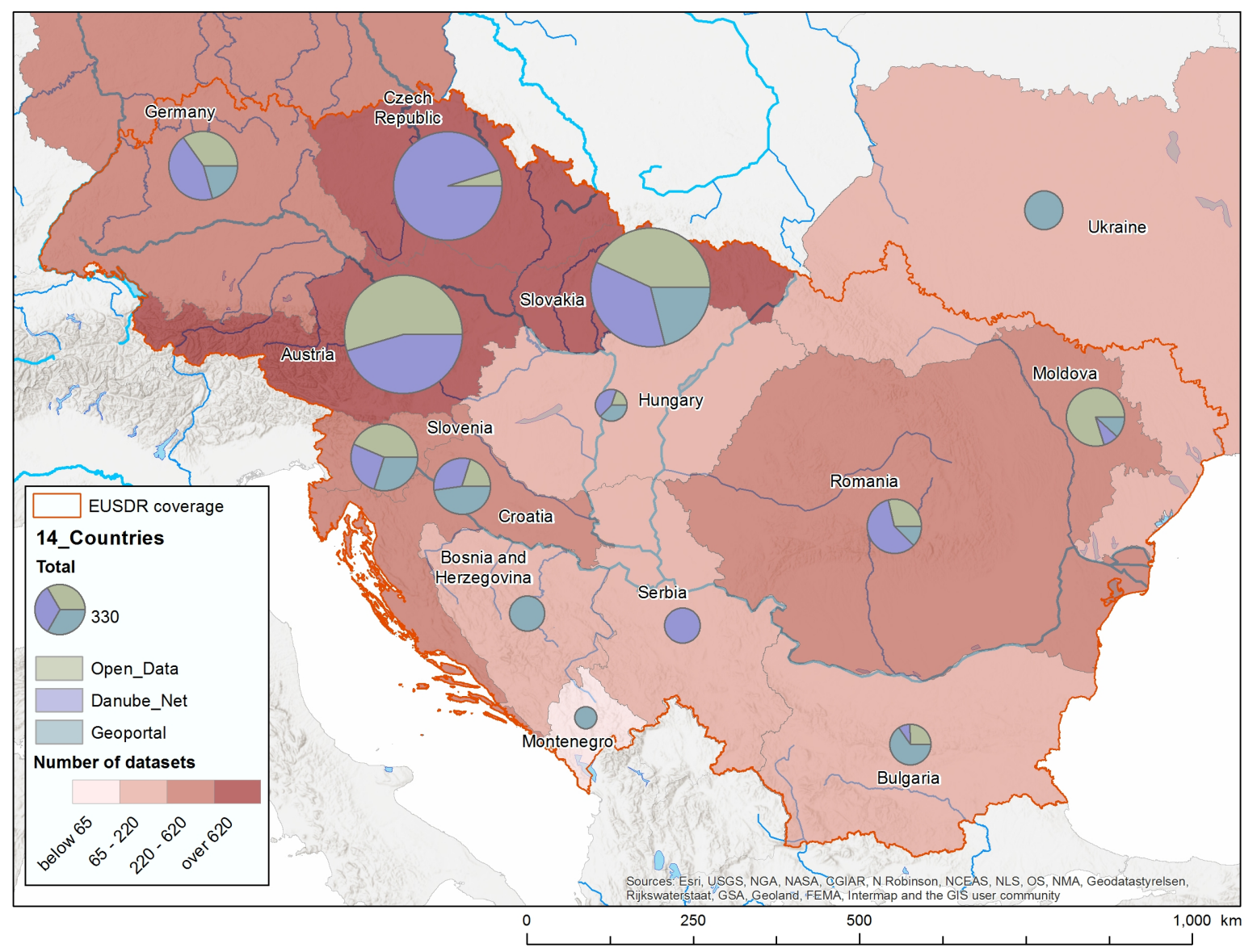

Figure 6. Data availability in the Danube region open data portal. Source: [12].

\subsubsection{Danube_Net}

In addition to the open data described above, we used the state-of-play reports on the national spatial data infrastructures that were produced by the Danube_Net-a network of 14 experts, representing each country in the study area [28]. The reports covered a broad spectrum of topics in a coordinated manner. They included an overview of tools used to serve data and metadata, licensing frameworks, metadata profiles and standards, together with noteworthy use cases for the application of data sets and services for policy making purposes. The country reports showed many commonalities and similar challenges associated with the establishment of usable spatial data infrastructures in the region. In general, they relate to the capacity of public sector actors to scope, implement and maintain data infrastructures that are best tailored to the evolving requirements of heterogeneous stakeholders.

While analysing the state-of-play reports we paid particular attention on the section dedicated to existing data gaps. We used this input information to validate the evidence on the availability of data obtained through the open data portal described in Section 3.1.1.

\subsection{Gap Analysis}

The analytical material described under Section 3.1.2, together with a cross-check in the Danube data catalogue (Section 3.1.1) helped us to identify data niches for each country that could possibly be addressed by Citizen Science activities. Those were split into nine categories (Table 1) in accordance with the requirements of the 'Scientific support to the EUSDR', defined by the European Commission [29]. It is worth highlighting that certain categories can overlap (e.g., energy production vs. bioenergy, irrigation vs. agriculture development, land vs. soil), but they are provided separately in the manuscript for simplicity reasons. It should also be noted that we did a first analysis on the level 
of those categories. Most—if not all—of them require a rich portfolio of datasets in order to be fully addressed by regional-development policy. However, such level of detail is out of the scope of our initial investigations that aim at a horizontal overview, i.e., as a baseline for future work.

Table 1. List of categories for identification of possible data gaps. Source [29].

\begin{tabular}{cl}
\hline Nr. & Category \\
\hline 1. & Environment protection \\
2. & Navigability \\
3. & Irrigation and agricultural development \\
4. & Energy production \\
5. & Air \\
6. & Water \\
7. & Land and Soil \\
8. & Bioenergy \\
9. & Others (none of the above) \\
\hline
\end{tabular}

The data gaps that were identified by each Danube_NET expert were extracted from a series of reports. They are summarised in Table 2.

Table 2. List of data gaps in the Danube region. Source: Danube_Net country reports [28].

\begin{tabular}{|c|c|c|}
\hline Country & Data Gaps & Category \\
\hline Austria & $\begin{array}{l}\text { Power plants } \\
\text { Livestock farms }\end{array}$ & $\begin{array}{l}\text { Energy production } \\
\text { Irrigation and agriculture }\end{array}$ \\
\hline Bosnia \& Herzegovina & $\begin{array}{l}\text { (The country report does not contain substantial evidence } \\
\text { unknown can to be used for identification of possible data gaps.) }\end{array}$ & \\
\hline Bulgaria & $\begin{array}{l}\text { Bio-heat on local scale } \\
\text { Data on utilities } \\
\text { Livestock farms } \\
\text { Forest mills } \\
\text { Data on health } \\
\text { Land use master plans }\end{array}$ & $\begin{array}{l}\text { Bioenergy } \\
\text { Energy production } \\
\text { Irrigation and agriculture } \\
\text { Irrigation and agriculture } \\
\text { Others } \\
\text { Land and Soil }\end{array}$ \\
\hline Croatia & Data on bioenergy & Bioenergy \\
\hline Czech republic & Land use in rural areas & Land and Soil \\
\hline Germany & Human health & Others \\
\hline Hungary & unknown & \\
\hline Montenegro & Renewable energy sources & Energy production \\
\hline Moldova & $\begin{array}{l}\text { Bioenergy data } \\
\text { Energy production data } \\
\text { Data on transportation }\end{array}$ & $\begin{array}{l}\text { Bioenergy } \\
\text { Energy production } \\
\text { Navigability }\end{array}$ \\
\hline Romania & Data on energy & Energy production \\
\hline Serbia & unknown & \\
\hline Slovakia & $\begin{array}{l}\text { Multi-modal transportation network } \\
\text { Production and use of energy resources } \\
\text { Culture and tourism }\end{array}$ & $\begin{array}{l}\text { Navigability } \\
\text { Energy production } \\
\text { Other }\end{array}$ \\
\hline Slovenia & EUSDR priority areas well covered & \\
\hline Ukraine & unknown & \\
\hline
\end{tabular}

\section{Citizen Science Contribution}

After having identified data gaps in the region on a high level of abstraction we reviewed existing Citizen Science solutions that could be directly applied for closing or narrowing the existing shortcomings. Only as a second step, and where no match to an existing effort could be identified, we considered the establishment of a new activity (Figure 5). Again, we conducted this research as a first activity in order to approach the topic and did not get into as much detail as data quality needs and details of the data provisions from the individual Citizen Science projects. 


\subsection{Identification of Existing Activities}

We used heterogeneous channels in order to identify Citizen Science activities for the Danube region, such as web search, the CORDIS project repository database [30], initiatives as described under Section 2.3.3, and Danube_Net country reports. Priority was given, in accordance with the macro-regional dimension targeted, to national and international initiatives. Twenty relevant project initiatives were identified and further investigated for concrete examples where data can be used as input to policy making. An overview of the allocation of project data to individual countries and themes that are covered (Figure 7) shows that the majority of activities are available within EU Member States, however some isolated activities also cover the Western Balkans, Moldova and Ukraine.

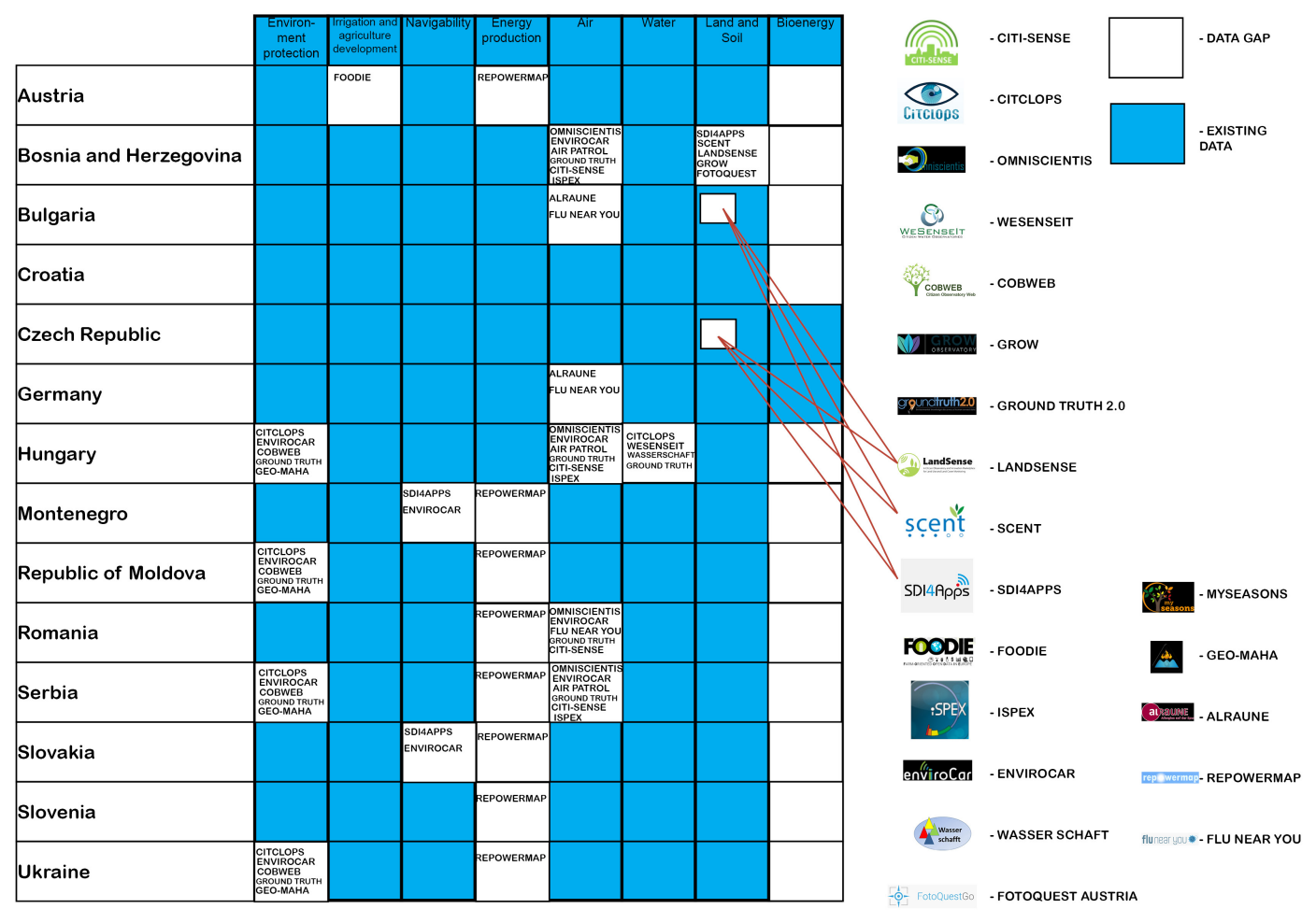

Figure 7. Thematic and geographic coverage of Citizen Science projects in the Danube region.

Thematically, there is a significant predominance of projects addressing environmental topics with the highest percentage addressing the quality of ambient air. This might be traced back to the origins of the term 'Citizen Science', which is rooted in the environmental domain, and to the recent focus of Citizen Science funding that concentrated on environmental pollution, and especially on air quality. Some reference projects that we investigated in relation to the category "Air" include CITI-SENSE, envirCar and iSPEX.

- The CITI-SENSE project [31] developed a rich web portal and toolbox (http:/ / co.citi-sense.eu/) that can be re-used to measure air pollution and the human perception of air quality at any given occasion by using low-cost sensors and mobile phone applications. Methods and tools are provided to capture information about both, indoor and outdoor air quality.

- enviroCar is a Citizen Science platform for analysing and mapping crowd-sourced car sensor data [32]. The research project proposes an innovative approach towards the monitoring of car-related air pollution. Data is collected directly from the cars of volunteers. It is afterwards contributed to an open platform (https://envirocar.org/). An application programming interface (API) is made available to ensure easy access to the citizen-generated content. From our 
perspective this alternative approach to data collection is highly promising. Mashing up the resultant observations with other data sources (e.g., air quality models, data from monitoring stations, etc.) would lead to improved data coverage for air related matters.

- The iSPEX project [33] established a measurement network for particulate matter through the use of a smartphone app equipped with a specialised add-on. The project engaged with a vast number of volunteers, and illustrated the benefits of Citizen Science for obtaining a high resolution representation of the studied phenomenon.

\subsection{Development of a New Citizen Science Application}

We found that most gaps might indeed at least in parts benefit from the transfer and extension of already ongoing Citizen Science activities to a new geographic area. Only for the case of bioenergy, we could not find any even partially matching solutions involving citizens. Interestingly, exactly this topic is high on the European political agenda on the circular economy, an initiative to make the economy more sustainable and competitive [34]. In the case of bioenergy this refers to the re-use of biomass (as a renewable natural resource) to create energy, e.g., in the form of heat.

We decided to outline a new activity, also in order to illustrate with one concrete example how this last gap might be addressed. We used, an event organised in the study area, the DanubeHack 2.0 [35], as an opportunity to work on concrete ideas that could possibly fill existing data gaps related to bioenergy. The discussions resulted in the selection and initial development of a smartphone application (app) called 'Waste2Fuel'. The app is described below from a conceptual and technical point of view.

\subsubsection{App Rationale}

Agriculture has for long been an important source of income for many people in the Danube region. Agricultural production is diverse, but vineyards and orchards are traditionally well represented throughout the whole region. Those vineyards and orchards must be pruned twice a year-a well known agricultural practice which leads to many piles of residual branches (Figure 8). Usually, the owners directly burn the residual material in the field, not only creating environmental problems, but also missing opportunities for a better utilization of the biomass.

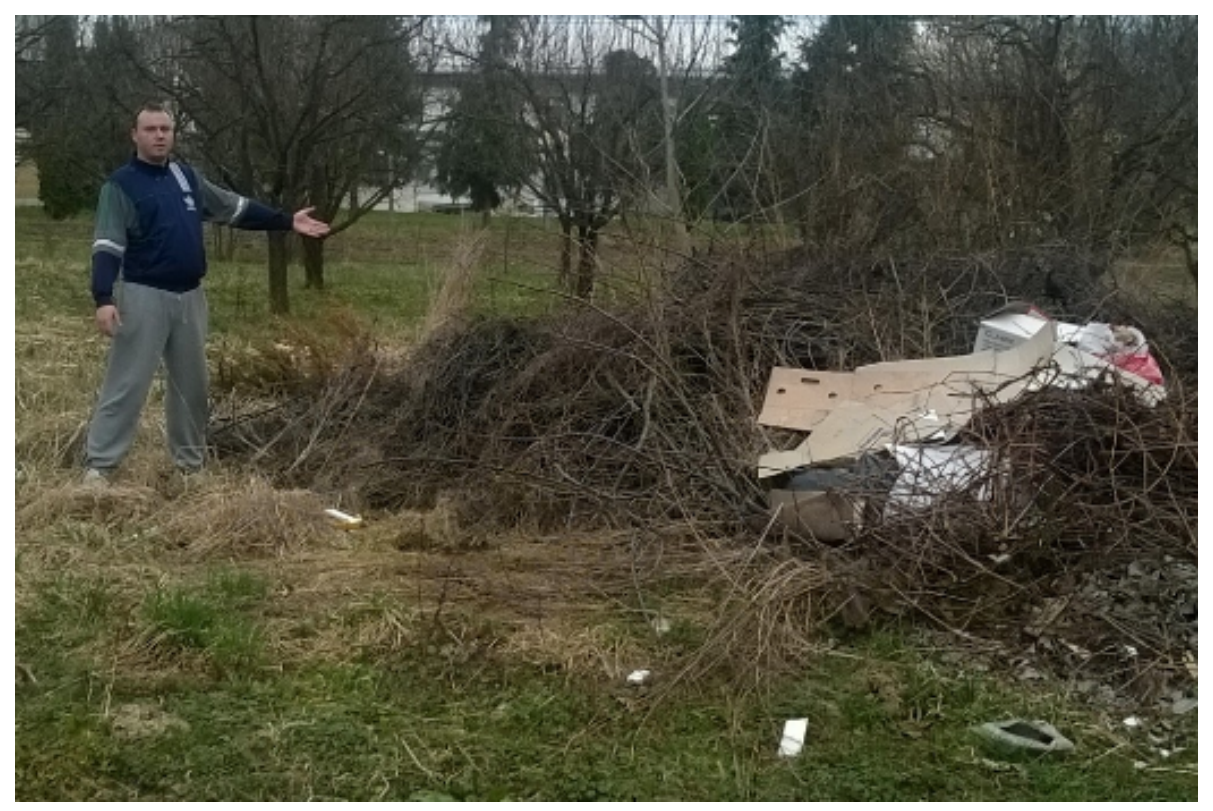

Figure 8. Example of a pile of residual branches in the Danube region. 
At the same time, the overall supply of biomass in the Danube countries (excluding non-EU countries where data was not available) is estimated for 2009 to be 1136.2 petajoule (PJ) with an agriculture contribution of $23 \%$ [36]. If seen from the perspective of bioenergy the residual branches provide an excellent raw material for the production of wood pellets for heating. Furthermore, it appears reasonable to assume that there is shared interest in utilising this resource between biomass producers and vineyard and orchard owners. However, information about the location and volume of the piles that are available for further consumption is not passed from one to the other and pick-ups cannot be organised.

\subsubsection{App Conceptualisation}

Within the context described above, an app was scoped that, based on the shared interest of different stakeholders, would enable (i) owners of vineyards and orchards to collect and share data on branch piles, including the volume and locations using smartphones, and (ii) biomass producers to be notified of the available biomass location(s) and estimated volume, see a photo as evidence, so that they can arrange the pick up of the branches for further processing.

In addition, it was considered important to share information about potential risks and to alarm owners in vicinity of forest areas in order to avoid wildfires. With this approach we hope to not only warn the owners of vineyards and orchards, but to also motivate them not to burn the piles.

With this setup, the application would benefit a whole set of stakeholders, including:

- Citizens (site owners) that do not have to organize burning activities.

- Industry (biomass producers) that get access to more biomass.

- Civil society for which (i) security is increased by less uncontrolled burning activities, and (ii) pollution from combustion is decreased.

- Research organisations that get access to one more spatial dataset about bioenergy in the Danube region.

- Governmental organisations that have less data gaps and can better support developments in the region.

\subsubsection{Waste2Fuel Initial Development}

An app was developed and tested in December 2016. It was developed entirely through the use of open source components. The source code is committed to GitHub [37]. A test instance is available at https:/ / www.pg.geof.unizg.hr/biomass/. The current version of the application uses the following datasets:

- CORINE Land Cover 2012-Land cover inventory obtained through satellite image and in situ data processing [38].

- Land Parcel Identification Systems (LPIS)—systems, put in place by European Union Member States for identification of land plots based on high resolution aerial imagery.

- Open Land Use Map-Open, harmonised and seamless database of open land use in the Danube region obtained through combining input from heterogeneous data sources [39].

- Land Use/Cover Area frame statistical Survey (LUCAS)—sample statistical survey carried out by Eurostat every three years [40].

\subsubsection{App Functionality}

When a user is at the location of a pile of branches, (s)he can select 'Add biomass site', and a data form opens with fields to input a short description, contact number and estimated volume of the pile (Figure 9). In the end of the session, users can shoot and upload a photo. 


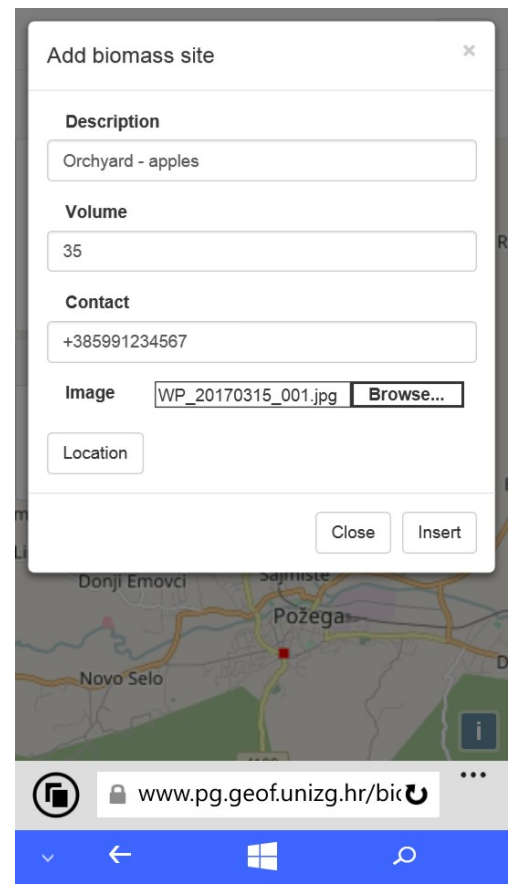

Figure 9. User interface of Waste2Fuel for adding a biomass sighting.

Data are uploaded to a server, and a new point is added to the 'Biomass sites' dataset which is also visible on the map. Biomass producers can use the interface (Figure 10) in order to find and select piles that they want to pick up.

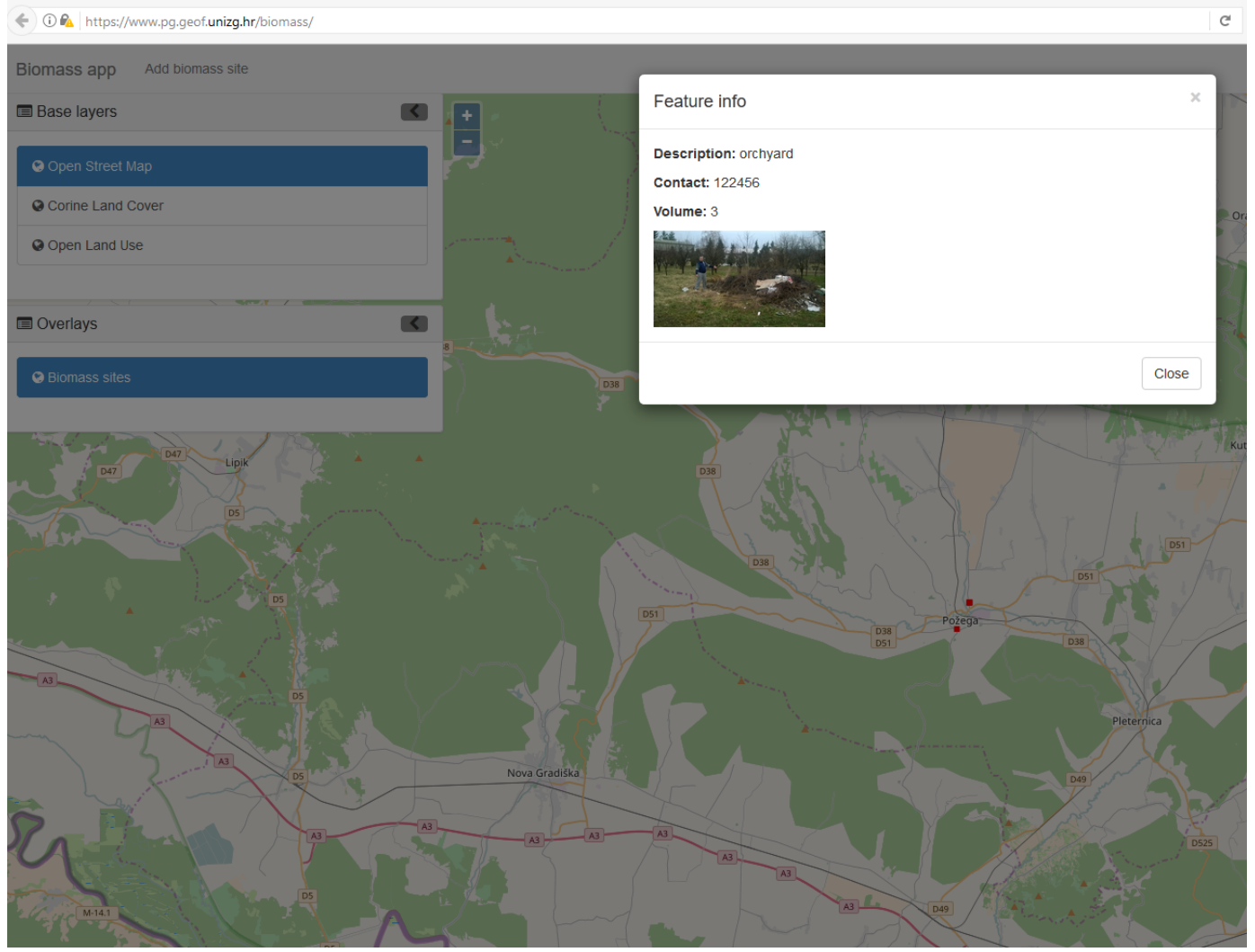

Figure 10. Web interface of Waste2Fuel. 


\section{Discussion}

Apart from the highly practical issues of enabling citizens to contribute to the closing of data gaps in a macro-region, the approaches indicated above introduce a particular way of public participation in relation to development policy. Members of the public start to get into a position in which they may contribute to the evidence base that is used for policy making - by directly providing data themselves, but also by taking actions related to policy targets. In addition to the projects presented in Section 4.1, the Waste2Fuel app described in Section 4.2 provides an illustrative example of how citizens may provide information about biomass that is available in the Danube region. At the same time, they help companies to arrange for the pick-up and support the re-use of branches that would have otherwise been wasted. Here we provide our perspective on the opportunities and challenges associated with the role of citizens, empowered by modern IT tools, throughout the policy cycle.

\subsection{Citizens' Impact on Policy Making}

The opportunities to get more citizens actively engaged are manifold, i.e., members of the public (including citizen as well as commercial enterprises) can be offered a rich portfolio of possibilities, which they might consider. The work presented here illustrates many of the already existing options to involve citizen in the closing of data gaps. We identified and listed a rich set of already existing solutions that could be deployed and offered to people living in, or visiting the Danube region. Notably, efforts would still be required in order to modify existing solutions (if necessary) to match the exact data needs; set-up the required data management infrastructures; prepare solutions in order to be ready for use in the region (e.g., including dedicated training material, as well as, language translations); and promote their existence to members of the public.

\subsection{Challenges}

Before engaging with citizens, it should also be noted that the emerging new options for increased public engagement do also come with a series of drawbacks. The pros and cons of collecting data through Citizen Science approaches are widely addressed in the literature (see for example [41-45]). The following critical issues should be recognized:

- Data coverage. The heterogeneous spatio-temporal coverage of citizen data might swamp any signal, or produce spurious signals of change where none exists [46]. At the same time, the coverage of data that fits policy makers' needs is (i) hard to define, and (ii) difficult to implement in practice. Data from Citizen Science apps, for example, is closely bound to where a community is involved for a particular reason. It often hardly exceeds the local dimension (e.g., bounds of a municipality). Community building activities are thus likely to be required in order to close a particular data gap on higher administrative levels or less-urban areas.

- Combined use of data. The integration (or mashing-up) of data, even if feasible and relatively easy from a technical point of view, should be based on solid theoretical foundations and where possible cross-checked with other data sources. This is important for Citizen Science approaches because it is, for example, very difficult to determine whether a particular high concentration (or lack) of data for a particular area, is objectively representing the studied phenomenon, or is related to a particularly active (or inactive) community. Notably, tools and methods from multiple projects might be combined to best address a data need. Also, in some cases, Citizen Science might be the only possible way to collect a particular data set, for example, for mapping uncharted territories (see for example [47]) that cannot be surveyed through traditional methods such because of military conflicts, dictatorships, or environmental crises.

- Data validation and quality. Validation and quality assurance of gathered data are a common issue for any data collection, but are frequently challenged in relation to Citizen Science activities. Related challenges and solutions are widely discussed in the literature (for example [48-51]). Whereas evidence shows that, for example, for species identification, non-professionals may reach 
a high level of expertise and eventually even outperform professional scientists. It might also be feasible to use Citizen input as a proxy for resource optimization, as, for example, done in a collaboration between the Scottish Environmental Protection Agency (SEPA) as part of the Anglers' Riverfly Partnership (http:/ / www.riverflies.org/rp-riverfly-monitoring-initiative).

- Fitness for purpose. Specific analysis of the appropriateness of a particular Citizen Science approach with respect to the concrete policy making needs would be needed when addressing any of the identified data gaps. The suitability of a solution that has already been developed will most essentially depend on two factors. The tools that are provided by the project, e.g., (i) Can a concrete air quality sensor meet the quality needs that are required in order to improve the model of environmental pollution at a regional level (also considering the density and costs of already existing measurement networks)? (ii) Does the smartphone for monitoring selected species deliver reliable occurrence records? And the methodology required by the project in order to mobilize or gather data, e.g., (a) Can the approach cover an entire region or country at a given resolution? (b) Can the data gathering be repeated in well-defined cycles in order to support monitoring? These investigations need to be carried out on a case-by-case basis (per required data set and per possible suitable Citizen Science project). They might be accompanied by a cost-benefit analysis.

- Business models. Following from the above mentioned assessment of cost-effectiveness, we also want to emphasise on the need for robust business models. Citizen Science activities require much more resources than possible technology (hardware and software). It also requires capacity building, community management and sustainability of the gathered results. Here, we should separate between the funding models of Citizen Science projects as such-see, for example [52] —from operational (and possibly long-term) use. While equal needs might be argued for other scientific and governmental approaches to data collection, analysis and dissemination, Citizen Science requires a different set of skills in order to, for instance, meet certain ethical requirements. However, as diverse as Citizen Science is in itself, as diverse are possible business models. Especially the embodied concept of shared responsibility offers a new range of possibilities, for example, Non-Governmental Organisations (NGOs) enter the scene, which might provide support in community outreach, and in some cases Citizen Science communities entail their community managers. Equally, a Citizen Science approach might help to optimise and concentrate available resources where they are most needed. Last but not least, Citizen Science approaches may also help reaching other goals of the involved parties, such as the modernisation of public services or the improved relationship between people and governments. Resource pooling is thus an option.

- Expectation management. Governmental support of a Citizen Science application (e.g., via a mobile phone app) raises expectations. Especially, citizens are likely to expect an immediate (re)action after having provided information. However, in regional policies across country borders, reactions are not always immediate, particular not if it is used as extended scientific advice in evidence based policy making. Decisions will take place along the policy cycle and diverse/heterogeneous political and cultural landscapes each add their own temporal constraints. The use of the data and according feedback mechanisms have to be clearly communicated from the beginning of each Citizen Science initiative.

- Participant incentives. The incentive of citizens to contribute to data collection initiatives beyond the initial curiosity is to be investigated. Not only need people be mobilized and attracted to participate in a Citizen Science activity, but active contributors have to be retained, too. Multiple mechanisms exists, but have to be selected carefully. One of the options would be to benefit from already active communities and engage with them in order to make a data collection exercise valuable for all participants in the process. 


\section{Conclusions}

Our initial investigations of the Citizen Science topic in relation to regional development set a rich baseline for future research. We wrap the most central messages, main lessons and areas for future work below.

\subsection{Summary}

The implementation of macro-regional policies relies on the availability and accessibility of data covering multiple topics. Whereas, also thanks to the growing popularity of open data policies, many of the required data sources do become available, gaps still exist. This holds particularly when multiple countries are involved, that all have their individual cultures and political priorities. We illustrated such a situation based on our experiences in the Danube macro-region and our involvement in the DRDSI project.

Among the four possible ways for closing, or at least narrowing data gaps, we highlighted several possibilities of involving citizens directly in data collection. We outlined that each of the data gaps that we identified for the Danube region could be addressed, at least partially. Surprisingly, almost all priority areas of the Danube Strategy may be addressed by transferring an already existing solution into a geographical area that was not covered so far. For the only topic that remained competently uncovered (bioenergy), we highlighted several possible solutions, situated in the circular economy, and especially related to energy production from organic material. We already succeeded to prototype an application thanks to a hackahton [35] that took place in Bratislava in 2016.

Whilst highlighting the many options that already exist today, we also underlined some of the critical issues that would need to be considered when allowing public participating in rational development policy following any of these Citizen Science approaches.

\subsection{Main Lessons}

The involvement of citizens not only provides an opportunity for closing data gaps, but also brings the policy making process closer to people. That is why the potential of Citizen Science to improve the dialogue between citizens and governments should not be underestimated. Within this context however, it is important to respond adequately to the raised expectations of citizens, and use appropriate communication channels. With our work we illustrated how data from citizens could play an important role in complementing other data sources. Nonetheless, there are numerous challenges that need to be addressed, for a real policy uptake of Citizen Science data. The questions below need an answer in order to decide whether an approach including citizens is at all feasible:

1. Are there existing data which are possible to 'open' in order to close the gap?

2. If yes, how much does it cost to open the data?

3. If other sources are too expensive, is there a Citizen Science activity (completed, ongoing, or planned) that might close the gap?

4. Would the quality of data from citizens be satisfactory?

5. How to ensure sustainability of the data collection process?

\subsection{Future Work}

In closing, citizen generated content is very likely to be an increasingly important channel for gathering policy relevant input. Furthermore, data from citizens might be more cost-effective and collected faster in comparison with other source of data. Trustworthiness and quality of the data generated through citizen engagement should still be investigated, and we will be addressing those issues as continuation of the work presented here.

Recognizing this article as a first approach to the topic, and considering the critical issues already raised in Section 5, there are several interdependent topics to be further investigated. These include: 
- Data gaps and possible Citizen Science contributions need to be further analysed on a case by case basis. This should include closer investigations of the data needs (e.g., in terms of coverage and quality), possibilities and limitations of using an already existing Citizen Science approach (transportability, need of community building etc.), but also a critical reflection on possibly underlying assumptions (e.g., on social needs).

- The potential of the app described in Section 4.2 is not explored to its full potential. Its possible use as a standalone tool, or in combination with one or more of the traditional approaches should be further investigated. Also, the deployment in the involved communities should be tested with a limited set of participants before approaching broader use.

- Methodologies for mobilizing and retaining citizens to contribute on a regular basis (i.e., beyond the initial curiosity) should be tested and then rolled out more widely. This will have to account for repeated promotion activities, but equally for feedback provision and ensured use of the inputs provided by the citizen.

- A scientifically sound methodological framework for utilisation of citizen contributions still needs to be developed and tested in real world conditions. Such investigations might need to reflect about the quality criteria to be applied and the relationship to e.g., official statistics and indicator-based assessment.

- Successful organizational settings to orchestrate the engagement processes need to be identified, shared and adopted where needed. When talking about regional development policy, the amount and diversity of involved stakeholders makes this exercise particularly channelling and highly interesting.

Acknowledgments: The manuscript is developed within the "New data sources and Citizens Science platform"
project of the Joint Research Centre, European Commission. The authors would like to thank Saša Vranić,
Hrvoje Tomić and Tomáš Kliment for their work on the Waste2Fuel prototype. We would also like to express our
gratitude to Jean Dusart and Robin S. Smith for scoping relevant work within the DRDSI project, as well as to Mrs.
Brooke Tapsall for proofreading the final draft of the text.

Author Contributions: J.L. worked on all chapters of the manuscript, analysed input from the Danube_Net reports and other sources of data, scoped and worked extensively on the Waste2Fuel prototype. S.S. contributed to the overall storyline, positioning of the specific work on Citizen Science into the wider research context, as well as the consolidation of the conclusions and shaping of future work. A.K. contributed to all chapters of the paper, including the literature review, as well as on defining the policy context, issues related to data management and the Danube Reference Data and Servies Infrastructure.

Conflicts of Interest: The authors declare no conflict of interest.

\author{
Abbreviations \\ The following abbreviations are used in this manuscript: \\ CKAN Comprehensive Knowledge Archive Network \\ CORDIS Community Research and Development Information Service \\ CS Citizen Science \\ DRDSI Danube Reference Data and Services Infrastructure \\ EUSDR European Union Strategy for the Danube Region \\ ECSA European Citizen Science Association \\ JRC Joint Research Centre, European Commission \\ OGC Open Geospatial Consortium
}

\title{
References
}

1. G8 Open Data Charter. Available online: https://www.gov.uk/government/publications/open-datacharter (accessed on 10 Feburary 2017).

2. Open Data Barometer. Available online: http:/ / opendatabarometer.org/ (accessed on 29 March 2017). 
3. Masser, I.; Crompvoets, J. Qualitative monitoring of information infrastructures: A case study of INSPIRE. Environ. Plan. B Plann. Des. 2016, doi: 10.1177/0265813516675871.

4. Butcher, G.S.; Niven, D.K. Combining Data From the Christmas Bird Count and the Breeding Bird Survey to Determine the Continental Status and Trends of North America Birds; National Audubon Society: New York, NY, USA, 2007.

5. Grey, F. Citizen Cyberscience: The new age of the amateur. CERN Courier 2011, Volume 51(7), 41-43.

6. Hemment, D.; Ellis, R.; Wynne, B. Participatory mass observation and citizen science. Leonardo 2011, 44, 62-63.

7. Chun, S.A.; Shulman, S.; Sandoval, R.; Hovy, E. Government 2.0: Making connections between citizens, data and government. Inf. Polity 2010, 15, 1-9.

8. Coglianese, C. Citizen participation in rulemaking: Past, present, and future. Duke Law J. 2005, 55, 943-968.

9. Fung, A. Putting the public back into governance: The challenges of citizen participation and its future. Public Adm. Rev. 2015, 75, 513-522.

10. DRDSI Open Data Portal. Available online: http://drdsi.jrc.ec.europa.eu (accessed on 29 March 2017).

11. EUSDR Website. Available online: https: / /www.danube-region.eu (accessed on 29 March 2017).

12. Dusart, J.; Kotsev, A.; Smith, R.S.; Cetl, V.; Tapsall, B.; Divjak, D. Data Infrastructures in Support of Macro-Regional Development. Experiences and Lessons Learned From the Danube Region; European Commission: Brussels, Belgium, 2016.

13. Kotsev, A.; Dusart, J.; Smith, R. Reference Data and Services Infrastructure for the Danube Region. J. Entrep. Innov. 2015, 7, 143-147.

14. Haklay, M. Citizen science and volunteered geographic information: Overview and typology of participation. In Crowdsourcing Geographic Knowledge; Springer: Berlin/Heidelberg, Germany, 2013; pp. 105-122.

15. European Strategy for Open Science. Available online: https://ec.europa.eu/digital-single-market/en/ open-science (accessed on 29 March 2017).

16. European Actions on Citizen Science. Available online: https:/ / ec.europa.eu/digital-single-market/en/ citizen-science (accessed on 29 March 2017).

17. See, L.; Mooney, P.; Foody, G.; Bastin, L.; Comber, A.; Estima, J.; Fritz, S.; Kerle, N.; Jiang, B.; Laakso, M.; et al. Crowdsourcing, citizen science or volunteered geographic information? The current state of crowdsourced geographic information. ISPRS Int. J. Geo-Inf. 2016, 5, 55.

18. Silvertown, J. A new dawn for citizen science. Trends Ecol. Evol. 2009, 24, 467-471.

19. Bonney, R.; Cooper, C.B.; Dickinson, J.; Kelling, S.; Phillips, T.; Rosenberg, K.V.; Shirk, J. Citizen science: A developing tool for expanding science knowledge and scientific literacy. BioScience 2009, 59, 977-984.

20. Craglia, M.; Shanley, L. Data democracy-increased supply of geospatial information and expanded participatory processes in the production of data. Int. J. Dig. Earth 2015, 8, 679-693.

21. Launch Event: Citizen Science at LERU Universities. Available online: http://www.leru.org/index.php/ public/calendar/citizen-science-at-leru-universities-trends-guidelines-and-recommendations (accessed on 29 March 2017).

22. SciStarter Website. Available online: https:/ / scistarter.com (accessed on 29 March 2017).

23. European Open Science Policy Platform. Available online: https://ec.europa.eu/research/openscience/ index.cfm?pg=open-science-policy-platform (accessed on 4 April 2017).

24. Responsible Research and Innovation. Available online: https:/ / ec.europa.eu/programmes/horizon2020/ en/h2020-section/responsible-research-innovation (accessed on 4 April 2017).

25. H2020 Science with and for Society programme. Available online: https://ec.europa.eu/programmes/ horizon2020/en/h2020-section/science-and-society (accessed on 4 April 2017).

26. Green Paper. Citizen Science Strategy 2020 for Germany. Available online: http://www.buergerschaffenwissen. de/sites/default/files/assets/dokumente/gewiss_cs_strategy_englisch.pdf (accessed on 26 July 2017).

27. Austrian Centre for Citizen Science. Available online: https://www.zentrumfuercitizenscience.at/en/thecenter (accessed on 22 May 2017).

28. DanubeNet State-of-Play Country Reports. Available online: http://drdsi.jrc.ec.europa.eu/state-of-play (accessed on 4 April 2017).

29. European Commission Memo. Scientific Support to the Danube Strategy, Brussels, 16 May 2013. Available online: http:/ / europa.eu/rapid/press-release_MEMO-13-441_en.htm (accessed on 26 June 2017).

30. CORDIS Database of European Research Projects. Available online: https://data.europa.eu/euodp/en/ data/dataset/cordisH2020projects (accessed on 28 April 2017). 
31. CITI-SENSE Project Website. Available online: http:/ / www.citi-sense.eu/ (accessed on 26 June 2017).

32. Bröring, A.; Remke, A.; Stasch, C.; Autermann, C.; Rieke, M.; Möllers, J. enviroCar: A Citizen Science Platform for Analyzing and Mapping Crowd-Sourced Car Sensor Data. Trans. GIS 2015, 19, 362-376.

33. Snik, F.; Heikamp, S.; de Boer, J.; Keller, C.; van Harten, G.; Smit, J.; Rietjens, J.; Hasekamp, O.; Stam, D.; Volten, H.; et al. iSPEX: The creation of an aerosol sensor network of smartphone spectropolarimeters. In Proceedings of the EGU General Assembly Conference Abstracts, Vienna, Austria, 22-27 April 2012; Volume 14, p. 12974.

34. European Commission Circular Economy Action Plan. Available online: http:/ / ec.europa.eu/environment/ circular-economy/index_en.htm (accessed on 4 April 2017).

35. DanubeHack 2.0 Website. Available online: www.danubehack.eu (accessed on 4 April 2017).

36. Banja, M.; Scarlat, N.; Dallemand, J.F.; Monforti-Ferrario, F.; Motola, V.; Bódis, K. Bioenergy Deployment in the Danube Region: Current Status And Progress According to National Renewable Energy Action Plans; European Commission: Brussels, Belgium, 2014.

37. Waste2Fuel GitHub Repository. Available online: https://github.com/danubehack/waste2fuel (accessed on 28 April 2017).

38. Corine Land Cover Dataset. Available online: http://land.copernicus.eu/pan-european/corine-land-cover (accessed on 28 April 2017).

39. Open Land-Use, SDI4Apps Project. Available online: http://sdi4apps.eu/open_land_use/ (accessed on 22 May 2017).

40. Land Use and Coverage Area frame Survey (LUCAS). Available online: http://ec.europa.eu/eurostat/web/ lucas/overview (accessed on 28 April 2017).

41. Burgess, H.; DeBey, L.; Froehlich, H.; Schmidt, N.; Theobald, E.; Ettinger, A.; HilleRisLambers, J.; Tewksbury, J.; Parrish, J. The science of citizen science: Exploring barriers to use as a primary research tool. Biol. Conserv. 2017, 208, 113-120.

42. Ottinger, G. Buckets of resistance: Standards and the effectiveness of citizen science. Sci. Technol. Hum. Values 2010, 35, 244-270.

43. Roy, H.E.; Pocock, M.J.; Preston, C.D.; Roy, D.B.; Savage, J.; Tweddle, J.; Robinson, L. Understanding Citizen Science and Environmental Monitoring: Final Report on Behalf of UK Environmental Observation Framework; Centre for Ecology and Hydrology: Oxfordshire, UK, 2012.

44. Comber, A.; Mooney, P.; Purves, R.S.; Rocchini, D.; Walz, A. Crowdsourcing: It matters who the crowd are. the impacts of between group variations in recording land cover. PLOS ONE 2016, 11, e0158329.

45. Meentemeyer, R.K.; Dorning, M.A.; Vogler, J.B.; Schmidt, D.; Garbelotto, M. Citizen science helps predict risk of emerging infectious disease. Front. Ecol. Environ. 2015, 13, 189-194.

46. Isaac, N.J.B.; van Strien, A.J.; August, T.A.; de Zeeuw, M.P.; Roy, D.B. Statistics for citizen science: Extracting signals of change from noisy ecological data. Methods Ecol. Evol. 2014, 5, 1052-1060.

47. Perkins, C. Plotting practices and politics: (im)mutable narratives in OpenStreetMap. Trans. Inst. Bri. Geogr. 2014, 39, 304-317.

48. Freitag, A.; Meyer, R.; Whiteman, L. Strategies employed by citizen science programs to increase the credibility of their data. Citiz. Sci. Theory Pract. 2016, 1, 2, doi:10.5334/cstp.6.

49. Lukyanenko, R.; Parsons, J.; Wiersma, Y.F. Emerging problems of data quality in citizen science. Conserv. Biol. 2016, 30, 447-449.

50. Wiggins, A.; Newman, G.; Stevenson, R.D.; Crowston, K. Mechanisms for data quality and validation in citizen science. In Proceedings of the 2011 IEEE Seventh International Conference on IEEE e-Science Workshops (eScienceW), Stockholm, Sweden, 5-8 December 2011; pp. 14-19.

51. Sheppard, S.A.; Terveen, L. Quality is a verb: the operationalization of data quality in a citizen science community. In Proceedings of the 7th International Symposium on Wikis and Open Collaboration, Mountain View, CA, USA, 3-8 October 2011; pp. 29-38.

52. Schade, S.; Tsinaraki, C. Survey Report: Data Management in Citizen Science Projects; Publication Office of the European Union: Luxembourg, 2016.

(C) 2017 by the authors. Licensee MDPI, Basel, Switzerland. This article is an open access article distributed under the terms and conditions of the Creative Commons Attribution (CC BY) license (http:/ / creativecommons.org/licenses/by/4.0/). 